\title{
Estudio diplomático de los testimonios de pregón del concejo medieval de Guadalajara (1454-1500)
}

\author{
José Miguel LóPez VILLALBA*
}

La Administración Pública emplea tres medios para informar de sus actos: la comunicación, la publicación y la notificación. Según el profesor Parada Vázquez: «la comunicación es el acto por el cual la Administración lleva a conocimiento de un sujeto, incluso de forma verbal, un determinado acto o hecho, en tanto que la publicación, es la comunicación a un colectivo indeterminado de personas" ' . Por su parte la notificación, variante más solemne y formal de la comunicación, es «la actuación mediante la cual ciertos funcionarios atestiguan haber entregado a una persona la copia de un acto" ${ }^{2}$. En tanto que actuaciones informativas, no se consideran actos administrativos propiamente dichos - puesto que tales actos se identifican con las resoluciones, no con la publicidad de los mismos-, pero son, sin embargo, la condición o trámite imprescindible para garantizar la validez jurídica de aquellos, pieza clave, por tanto, del estudio de la administración y de la historia de la administración, que parcialmente abordamos aquí desde el punto de vista de la Diplomática medieval y municipal.

Los vehículos actuales de la publicación administrativa municipal -de la comunicacion general- son muy variados: los paneles de información de los ayuntamientos, los boletines informativos de distribución general o los carteles colocados en lugares públicos, así como la prensa y los demás medios de difusión (radio, televisión, etc.). En otras épocas, que no han dispuesto de tales medios informativos, en la Edad Media, desde luego, la publicidad de las actuaciones se lograba mediante pregones. Este breve estudio trata de aquella antigua forma de publicidad administrativa, hoy casi olvidada, a partir fundamentalmente en los testimonios de

Universidad Nacional de Educación a Distancia.

Parada VázQuez, J.R.: Derecho Administrativo. Madrid, 1989. Tomo 1, p. 110.

lbidem, p. 110. 
pregones insertos en los libros de actas de sesiones del Concejo de Guadalajara conservados en el Archivo Municipal de esta ciudad ${ }^{3}$.

Los pregones fueron el medio más común para la publicación de los acuerdos concejiles medievales. No todos los acuerdos del Concejo precisaban del pregón, sino sólo aquellos que eran considerados de mayor importancia o que debían difundirse para garantizar la igualdad de oportunidades de los vecinos o la imparcialidad del gobierno local. Es el caso, por ejemplo, de las resoluciones relacionadas con el abastecimiento de la ciudad y su contratación ${ }^{4}$, con el arrendamiento de la recaudación de impuestos y arbitrios, o con el orden público - sobre todo en una ciudad como Guadalajara en la que no faltaron los disturbios a lo largo del siglo $X V$ - de la que veremos alguna sobre la tenencia y utilización de armas ${ }^{5}$. Además, lógicamente, de las disposiciones reales que también se publicaban por medio de pregones.

El pregón supone la existencia de un asunto, ordenado, solicitado o propuesto al Concejo para su discusión, de un acuerdo sobre el mismo, así como del mandato u orden de pregón. La actio del pregón se compone pues de estas fases previas, documentadas cada una de ellas individualmente. La conscriptio - que no siempre se cumple- es efectuada por el escribano con posterioridad al hecho mismo del pregón e incorporada al libro de actas de sesiones y destacada sobre la hoja en todas las ocasiones mediante un brevete que dice: «Pregón».

Ahora bien, desde el punto de vista de la Diplomática -que estudia en primer lugar las formas documentales - las fuentes que hemos consultado no permiten hablar sin ambigüedad de pregones, del mismo modo

\footnotetext{
3 Sobre otras fuentes, cfr. el estudio de Pino Rebolledo, F. Tipología de los Documentos Municipales (Siglos XII-XVII). Valladolid, 1991, pp. 170 y ss.

4 Cito sólo los tres trabajos recientes en los que podemos encontrar, además de un análisis pormenorizado sobre estas cuestiones para diferentes poblaciones castellanas bajomedievales, la bibliografia pertinente. Para la ciudad de Guadalajara, con una descripción del procedimiento de contratación, BARBAdillo Alonso, J. y GuTiÉrREz Dubla, N. «El debate del abasto del pescado a Guadalajara de 1500". En: IV Encuentro de Historiadores del Valle del Henares. Alcalá de Henares, (1994); pp. 93-102. Para Madrid, Puñal FeRnandez, T. El mercado de Madrid en la Baja Edad Media: Estructura y sistemas de abastecimiento de un Concejo medieval castellano: siglo XV. Madrid: Caja de Ahorros, 1992. Para Burgos: BonACHA HERNANDO, J.A. "Abastecimiento urbano, mercado local y control municipal: La provisión y comercialización de la carne en Burgos (Siglo XV)". En: ESPACIO, TIEMPO Y FORMA. Historia Medieval. UNED. Madrid (1992), № 5; pp. 85-161.

5 Pablo SÁNCHEZ LEÓN, en su tesis doctoral, defendida en diciembre de 1993, en la Universidad Autónoma de Madrid, que ha cubierto ciertas lagunas en el estudio de la Guadalajara bajomedieval, resalta la extrema conflictividad social a fines del siglo XV. Absolutismo $y$ Comunidad. Un análisis comparado del cambio político y de la conflictividad social en Castilla. Guadalajara y Segovia. Siglos XV-XVI. Tesis doctoral. En prensa.
} 
que hablamos de cartas, ordenanzas, bandos, etc., sino de certificaciones o testimonios de pregón. Dicho de otra forma: el pregón es un acto jurídico - un contenido, pero no una forma diplomática - que no da origen a un tipo documental específico, sino a una variante o subserie del tipo genérico que llamamos certificación o testimonio.

Hecha esta distinción queda por determinar la denominación crítica más correcta. Preferimos «testimonios de pregón» a «certificaciones de pregón» por varias razones: porque hemos observado que ese era el uso de la época y porque en la actualidad el término "certificación» está reservado en la práctica a aquellos documentos de fe pública iniciados por la intitulación («N. secretario etc. certifico que...»), mientras que el término «testimonio» advierte de antemano de una iniciación por la data tópica («En la ciudad de...») que es la fórmula empleada para dar fe de los pregones que hemos estudiado.

La estructura diplomática de los testimonios de pregón es simple. Los que hemos estudiado, que se hallan insertos, como dijimos, en las actas de sesiones, presentan a veces formas muy abreviadas, reducidas casi a una nota, sin mayor validación jurídica de la que les otorga el hecho mismo de haberse incorporado sin transición a un acta capitular:

Este dicho día, pregonó Juan Buenvezino como eran alcalldes de la hermandad los susodichos ${ }^{6}$.

En otras ocasiones, sin embargo, el formulario es más completo, hasta cumplir las partes clásicas diplomáticas. Así, se desarrolla el protocolo inicial, reducido en el caso anterior a la expresión "este dicho día», con la mención de la data tópica y crónica:

En la dicha villa, viernes XXVI de abril ${ }^{7}$.

Pino Rebolledo observa que las menciones de los lugares de pregón son excepcionales en la documentación que maneja ${ }^{3}$. Afortunadamente, las actas de Guadalajara objeto cie nuestro estudio, los registran con frecuencia: habitualmente, en el propio Concejo y ante las iglesias de San Gil - hoy plaza del Concejo- y San Andrés - ya desaparecida, en la actual calle Miguel Fluiters, primer tramo de la vieja calle Mayor-, no siendo escasas las referencias a la plaza de la picota y a la de Santa María ${ }^{9}$.

Archivo Municipal de Guadalajara.- Actas de Sesiones 1500 (63).

AMGU AS 1454 (39).

«Muy interesante es el conocimiento de los lugares donde se efectuaba el pregón, sin embargo en los Libros del Ayuntamiento no se hace mención de ellos, a no ser muy excepcionalmente". Op. cit., pp. 170-171.

9 Así, el 21 de diciembre de 1463, se pregonaban en las plazas de la picota y de Santa María de la ciudad ciertas ordenanzas sobre el vino.- AMGU. 1 H 52. 
También, aunque en una sola ocasión en todas las actas de sesiones conservadas, hemos encontrado citada la puerta del mercado, y ello por un motivo extraordinario, la celebración de una procesión para rogar por la salud del rey Enrique IV. Una ojeada al plano medieval de la ciudad atestigua el carácter estratégico de dichos lugares y la importancia del análisis de estas datas para estudiar los centros de actividad urbana ${ }^{10}$.

El cuerpo documental de los testimonios de pregón da cuenta, primero, de la ejecución del mismo:

Por mandado de los sobredichos e con acuerdo del señor marqués, se pregonó por Ferrando Martínez, pregonero, en el conçejo público e en la plaça de San Gil e en la plaça de Sant Andrés lo siguiente "1".

Luego se enuncia el contenido. Por ejemplo, para mostrar cómo el estudio de los pregones permite la recuperación de ordenanzas desconocidas:

Ninguna ni alguna persona non sean osados de vender carne muerta a/guna que sea en esta villa nin en sus arrabales, a rrastro nin a ojo, salvo cabritos ${ }^{12}$.

Que ninguno non corte nin trayga rrejas verdes de enzina o rroble ${ }^{13}$.

Que ningún nin algunas personas, vezinos e moradores de esta çibdat de Guadalajara e su tierra nin de fuera de ella non se acostunbra de cortar leña alguna de los montes de la Alcarria nin del Canpo de esta çibdad, salvo rrama de rrobles e enzinas, dexando pendones ${ }^{14}$.

Y también, como ejemplo del anuncio de subasta del arrendamiento de la recaudación de un tributo.

Que qualesquiera persona que quiera arrendar la moneda forera de este arçedianadgo como de otros qualesquier partidos de estos reynos que fuese a los contadores mayores de sus altezas e que la arrendaran ${ }^{15}$.

Atendiendo al contenido, Pino Rebolledo ${ }^{16}$, ha establecido dos grupos grupos de pregones: enunciativos y exhortativos. Al primero pertenecen aquellos cuya única función es la de anunciar los hechos del Concejo para

10 Un análisis sobre la asimetria del plano medieval de Guadalajara y las funciones de los espacios urbanísticos: BARBADLLLO ALONSO, J. y LóPEZ VILLALBA, J.M. «Un plano medieval irregular: Guadalajara". En: RENOVATEC. Barcelona. 22 (1991); pp. 24-30. También de los mismos autores: "La ciudad medieval de Guadalajara". En: Actas del IV Congreso de Medievalismo y Neomedievalismo en la Arquitectura Española. Avila, 1990. En prensa.

1 AMGU AS 1454 (24).

12 AMGU AS 1454 (39).

13 AMGU AS 1475 (42).

14 AMGU AS 1500 (88).

15 AMGU AS 1500 (32).

16 Pino Rebolleddo, op. cit., p. 177. 
general conocimiento; al segundo, aquellos que además llevan implícita una cláusula prohibitiva o un mandato, acompañados de las consiguientes sanciones. En aquellos pregones que por su carácter exhortativo se manda directamente alguna cosa, ordenándose taxativamente el cumplimiento de lo mandado, existen unas cláusulas penales que dan forma al texto. En dichas fórmulas se detalla la pena en que incurrirán aquellos que no cumplen lo ordenado. Estas penas pueden ser pecuniarias, corporales o de pérdida de propiedad de aquello que contraviniere las normas establecidas:

So pena que qualquier que lo contrario fiziere que incurra en pena de sesenta maravedís por cada vegada que le fuere provada ${ }^{17}$.

So pena de çient açotes e que pierda las bestias e leña ${ }^{18}$.

Que pague seysçientos maravedís de pena e ge lo puedan paçer syn pena alguna asy los melonares que pusyeren como los que son puestos ${ }^{19}$.

Cuando los tiempos no eran buenos las penas se agravaban llegan a extremos duros como el de despojar a los infractores de todos sus bienes:

So pena que prendan todos sus bienes para los muros de esta çibdat e los que non tuvieren bienes que les den çinquenta açotes e los que son ydos que vuelvan de aqui adelante a seys dias, so la dicha pena por quanto los tienpos andan turbados segund los bolliçios e escándalos que se dize entrado el rrey de Portugal en dichos rreynos ${ }^{20}$.

En otras ocasiones se hace referencia a penas supuestamente conocidas, por los receptores del anuncio, por estar previamente determinadas por las ordenanzas del Concejo.

so las penas estableçidas sobre ello por la dicha villa ${ }^{21}$.

Cuando el pregón cumple la misión de informar, el cuerpo documental se limita a desarrollar el anuncio de la comunicación pública, introducido siempre por la partícula "que»:

Que todos e qualesquier personas que quisieren vender trigo de los vezinos e moradores de tierra de la dicha villa que los truxiesen e vendiesen en la plaça de San Gil o Sant Andrés o por las calles públicas de la dicha villa e que no pagarían de alcavala por cada una fanega de trigo más de dos maravedíes, lo qual la dicha villa tenía egualado con los arrendadores de ella de este año ${ }^{22}$.

\footnotetext{
AMGU AS 1454 (39).

AMGU AS 1475 (42).

AMGU AS 1475 (95).

AMGU AS 1475 (139).

AMGU AS 1454 (74).

AMGU AS 1454 (64).
} 
Que sepan todos que son alcalldes de la hermandad de esta çibdad de Guadalajara, desde oy fasta seys meses primeros siguientes, Françisco de Villasirga, del estado de cavalleros e escuderos e Pedro de Toledo, mayordomo del estado del común de esta çibdat ${ }^{23}$.

Aunque Pino Rebolledo observa que la presentación de los pregones dentro de los libros de actas, carece siempre de escatocolo ${ }^{24}$, podemos afirmar que en el caso de Guadalajara aparece habitualmente una cláusula validatoria, que recoge los nombres de los testigos, separada con claridad del cuerpo del documento por punto y aparte. Las fórmulas utilizadas son las comunes, la relación de nombres y apellidos de los testigos, su cargo y vecindad:

Testigos, Garçia de Guadalajara, escrivano, e Juan Nuñez e Juan de Arguilló, vezinos de Guadalajara ${ }^{25}$.

Finalmente, no con la intención de presentar un modelo general, sino a modo de recapitulación, transcribimos a continuación un testimonio de pregón completo, de 1454:

En la dicha villa este dicho dia, miércoles diez dias del dicho mes de abril del dicho año, por mandato de los sobredichos e con acuerdo del señor marqués, se pregonó por Ferrando Martínez, pregonero, en el Conçejo público e en la plaça de San Gil e en la plaça de Sant Andrés lo siguiente:

Ninguno ni algunas personas non sean osados de traher armas ofensivas en público ni ascondido so pena que el que las truxere ge la tomarán e las perderá. E sy fuere escudero o cavallero, que estará tres días en la cadena, e sy fuere otro omme de qualquier manera que estará veynte dias en la cadenas. Otrosi, que ninguno ni alguno non sea osado de andar de noche después de la canpana de queda tañida sin candela, so pena que el que fuere tomado de otra manera, sy fuere cavallero o escudero que estará diez días en la cadena, e si fuere otro omme de qualquier manera que estara treynta dias en la cadena. Lo qual asi pregonado, en la manera sobredicha, Juan de Contreras, alguazil en la dicha villa, pidiólo por testimonio para guarda de su derecho.

Testigos, Alvar Páez de Castro e Lope de Ribera e Diego Garçía de Santestevan, vezinos de Guadalajara.

El Diccionario de Autoridades define el pregón como «La promulgación o publicación que en voz alta se hace en los lugares o sitios públicos, de alguna cosa que conviene que todos la sepan» ${ }^{26}$. Esta descripción olvida un aspecto esencial: el pregón debe ser dado por un oficial municipal

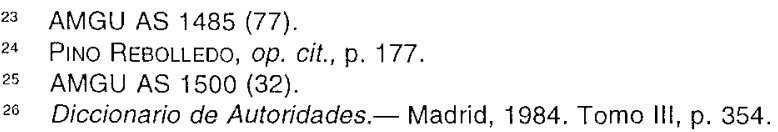


nombrado para ello, no por cualquiera. En las actas capitulares de Guadalajara hemos hallado un asiento que refleja el recibimiento en el oficio de la pregonería.

En XX de novienbre de mill e quinientos años, los honrrados el señor Diego Gonçalez de Guadalajara e [tachado: Francisco Sánchez de Guadalajara] el bachiller Diego Ródriguez de Sant Viçente, rregidores; rreçibieron por pregonero a Miguell Garçía, vezino de Guadalajara e sináronle de salario quiniestos maravedies en cada año e más sus derechos. Juró en forma.

Testigos, Juan de Alcalá e Juan Núñez, Rodrigo de Jaén, vezinos de Guadalajara ${ }^{27}$.

Hay noticias sobre los haberes percibidos por los pregoneros gracias a unas ordenanzas de derechos de los oficios del Concejo de Guadalajara, de 1463, coetáneos a la época estudiada, que ya hemos analizado en un trabajo anterior ${ }^{28}$. De dichas ordenanzas tomamos algunos casos, para concluir.

En primer lugar, por los pregones personalizados, es decir las actuales comunicaciones, se cobraba cuatro maravedies. Por pregonar treguas entre partes enfrentadas, dos maravedíes. Las cartas de los reyes, suponían tres maravedíes siempre que fueran causas civiles o criminales, pero si la comunicación real acogía mandamientos dirigidos a la ciudad, no podían llevar derechos, como no los llevaban por las ordenanzas u otros acuerdos del Concejo que fueran ordenados por los regidores. La paga, en todo caso, iba en proporción a la extensión del pregón: por pregonar una parte del cuaderno de alcabalas, tercias o montes, cuatro maravedís y por hacerlo en su totalidad, seis maravedís ${ }^{29}$. En todo caso, la pregonería municipal no era un oficio especialmente valorado; un viejo refrán lo recuerda: «Como subo, subo, de pregonero a verdugo».

27 AMGU AS 1500 (93).

28 LÓPEZ VILLALBA, J.M. «Estudio y transcripción de las ordenanzas de derechos de los oficios del Concejo de Guadalajara”. En: Espacios y Fueros en Castilla-La Mancha (Siglos XI-XV). Madrid, (1995); pp. 323-351.

29 Una breve cronología de los pregoneros de Guadalajara: 1454, Juan de Melgar y Fernando Martinez; 1475, Juan de Atienza, Juan López y Fernando de Villarreal; 1476, Juan López y Juan de Atienza; 1485, Martín Sánchez Blanco; 1496, Juan Viejo; 1500, Juan Buenvezino, Juan Raso de Ocaña y Miguel García. 